\title{
LA PRENSA GENERAL Y DEPORTIVA COMO FUENTE TEXTUAL FUNDAMENTAL PARA LA DOCUMENTACIÓN DE LOS PRIMEROS TÉRMINOS DEL FÚTBOL EN ESPAÑOL (1868-1899)
}

\author{
ANTONI NOMDEDEU RULL \\ Universitat Rovira i Virgili \\ antonio.nomdedeu@urv.cat \\ ORCID: 0000-0003-2447-6954
}

RESUMEN

En los últimos años se han publicado varias investigaciones que han tenido como objeto de estudio el análisis historiográfico de los términos del fútbol, pero, con todo, nos hallamos lejos de cubrir un vacío tan importante en la historia de la lengua española como lo es el de la descripción diacrónica del léxico futbolístico. En este contexto, el objetivo de esta investigación es presentar el corpus de textos periodísticos, entre 1868 y 1899, que conforman el Diccionario Histórico de Términos del Fútbol (DHTF) que estamos elaborando. A partir de los primeros registros léxicos documentados durante el siglo XIX en diversos textos periodísticos, los datos demuestran que $\mathrm{La}$ Vanguardia (periódico de información general) y Los Deportes (periódico deportivo) son los dos textos periodísticos fundamentales en cuanto a transmisión de léxico futbolístico se refiere.

PALABRAS CLAVE: historia del léxico español, diccionario histórico, léxico del fútbol, periódicos, siglo XIX.

\section{THE GENERAL AND SPORTS PRESS AS A FUNDAMENTAL TEXTUAL SOURCE FOR THE DOCUMENTATION OF THE FIRST TERMS OF FOOTBALL IN SPANISH (1868-1899)}

\section{ABSTRACT}

Several researches focusing on the historiographical analysis of terms of football have been published in the last years, however, we are still far from filling the very important gap in the study of the history of the Spanish language like the diachronic description of football lexicon. In this context, the aim of this study is to introduce the corpus of journalistic texts between 1968 and 1899 which constitute the Historical Dictionary of Terms of Football (DHTF) that we are developing. From the first lexical records documented during the $19^{\text {th }}$ century in different journalistic texts, data show that La Vanguardia (general information newspaper) and Los Deportes (sports magazine) are the fundamental journalistic texts when it comes to the transmission of football lexicon.

KEYWORDS: history of the Spanish lexicon, historical dictionary, football lexicon, newspapers, $19^{\text {th }}$ century.

\section{INTRODUCCIÓN}

El objetivo en este estudio es presentar los textos periodísticos del periodo comprendido entre 1868 y 1899 en los que se documentan las primeras voces del fútbol, base textual fundamental del Diccionario histórico de términos del fútbol 
(DHTF) que estamos llevando a cabo. ${ }^{1}$ La documentación de los términos en los textos periodísticos es prioritaria para poder construir la historia del léxico del fútbol español por dos razones: porque los primeros términos del fútbol se registran en español durante todo el siglo XIX solo en este tipo de fuente y porque los términos del fútbol se consolidan en este tipo de fuente.

Este estudio se circunscribe en un contexto investigador caracterizado por la necesidad de componer y describir una bibliografía que tenga por objetivo conocer con precisión la historia del nacimiento y consolidación del fútbol en diversos tipos de textos en español. Desde el punto de vista léxico, en los últimos años se han identificado varias investigaciones parciales que han tenido como objeto de estudio el análisis historiográfico de los términos del fútbol (Nomdedeu 2014, 2015, 2019 en prensa; Nomdedeu y Torrebadella 2016, 2018; Torrebadella y Nomdedeu 2013, 2014, 2015, 2016). Sin embargo, dicha bibliografía no es suficiente para cubrir un vacío tan importante en la historia de la lengua española como lo es el de la descripción diacrónica del léxico del fútbol. ${ }^{2}$ Se han elaborado varios diccionarios centrados en el léxico del fútbol ${ }^{3}$ o del deporte, ${ }^{4}$ pero son pocas las investigaciones que se hayan propuesto analizar el léxico del fútbol en los textos receptores de su terminología. Para cubrir este vacío existente, es básico partir de los textos que sirvieron para introducir y consolidar del léxico del fútbol en español. En ningún caso se ha abordado el estudio del léxico del fútbol desde una perspectiva interdisciplinaria, con las aportaciones de lingüistas, historiadores del deporte, especialistas en fútbol y documentalistas, lo que justifica plenamente la elaboración del DHTF.

\section{ConteXtualización}

Para describir el contexto en el que se hallaron las primeras documentaciones léxicas del fútbol (1868-1899) - primera fase del primer periodo (1868 y 1913) de los seis en los que hemos estructurado la historia del léxico del fútbol, ${ }^{5}$ titulado «inicios de la prensa deportiva y creación de un espacio propio»-, hay que valorar, como mínimo, tres factores.

\footnotetext{
${ }^{1}$ En http://www.dhtf.es pueden consultarse algunos artículos de muestra incompletos.

2 Puyal (1972), Gutiérrez Gutiérrez (1991), Castañón (1991 y 2005), Loureda (1997), Vivas (1998), Palacios (1999), Nomdedeu (2001, 2003a, 2003b, 2004a, 2004b, 2008a, 2008b y 2009b), Nomdedeu y Márquez (2001), Alba (2010 y 2011), Aleixandre et al. (2007), Gómez Torrego (2003, 2010a y 2010b), Gómez Torrego y Mapelli (2010), Saiz Noeda (2010), Pascual (2012), Ricco y Nomdedeu (2012), Pérez (2013), Torrebadella y Nomdedeu (2013 y 2014a).

${ }^{3}$ Polo (1996), Silveira (1996), Koch (1998), Peltzer (2007), Teruel (2007), Nomdedeu (2009a), Tolares (2009).

${ }^{4}$ Karag (1958), Agulló (2003), Real (2003), Castañón (2004), Loza y Castañón (2010), Pascual (2012).

${ }^{5}$ V. Nomdedeu y Torrebadella (2016).
} 
En primer lugar, no fue hasta la última década del siglo XIX cuando el fútbol comenzó a aparecer en varios tipos de textos (noticias, crónicas y artículos en prensa o revistas) con una cierta regularidad, en donde compartía espacio con otras muchas actividades atléticas o con temas no relativos al deporte. Hasta entonces, como así se documenta en Torrebadella y Olivera (2013), la caza y el ciclismo eran las actividades deportivas principales: la caza, por un lado, era la actividad recreativa tradicional entre las clases altas y más populares en los primeros años del deporte en España; por otro lado, la difusión gradual de la bicicleta como un instrumento de recreación para la población española y su irrupción como un deporte moderno y un símbolo de los nuevos tiempos le dio al ciclismo el mayor número de publicaciones en la prensa estudiada entre 1865 y 1899. ${ }^{6}$ Pero no fueron las únicas actividades de las que se trataba en los diferentes textos: equitación, esgrima o tenis (lawn tennis) eran unas prácticas deportivas que se fueron sumando paulatinamente a las propias de la aristocracia y de la alta burguesía ya mencionadas. Quienes practicaban estas actividades eran conocidos como sportsmen y eran burgueses que emulaban las modas o costumbres de la colonia anglosajona (Castro 2012, Lagardera 1996, Otero 2003, Pujadas y Santacana 2003, Torrebadella 2011), por lo común establecida en zonas de desarrollo industrial (Castro 2012, Torrebadella 2012, Torrebadella y Nomdedeu 2014). Como afirma Rivero,

en la década de los ochenta del siglo XIX, se practicaban deportes con orígenes militares y aristocráticos, relacionados con las salas de armas, la hípica, la náutica, los clubes de lawntenis y el automovilismo (...), deportes que se siguieron desarrollando en el nuevo siglo. (...) En los noventa, se crearía un movimiento gimnástico protagonizado por educadores, que fue seguido por sectores de clase media que veían en la actividad una fuerza "regeneradora" y positiva. (...) El deporte se fue popularizando y algunos sectores sociales de las ciudades españolas vieron en él una nueva variante de ocio y espectáculo. Tras la derrota del 98, todas estas actividades físicas empezaron a ser consideradas como un buen instrumento para la regeneración de la "afligida raza" y por tanto como algo beneficioso "para la patria". (Rivero 2005: 83)

El fútbol fue, en parte, un instrumento en la reacción española a la crisis del fin de siglo. En la misma línea, Torrebadella, Olivera y Bou han afirmado que:

Indeed, football bloomed in Spain at the time of the regenerationist movement following the political and institutional crisis that erupted in 1898. Regenerationist policies had an impact upon the emerging sports clubs, and football in particular was to become the setting where the new ideology would thrive. (Torrebadella, Olivera y Bou 2017: 3)

En segundo lugar, no fue hasta 1902 cuando surgió la necesidad de reglamentar el juego del fútbol y su léxico (Nomdedeu 2014), lo que se demuestra con la publicación del Reglamento de foot-ball de la Asociación de clubs de Football de Barcelona en ese mismo año. Hasta 1910, el fútbol aún se practicaba de

\footnotetext{
6 Para más detalles, v. Torrebadella y Olivera (2013), en donde se recopilan hasta 25 publicaciones específicas de esta actividad.
} 
forma rudimentaria, como un deporte esencialmente atlético y amateur, con un escaso conocimiento de las reglas (García-Castell 1968). La presencia de los términos del fútbol fue tan significativa en este periodo que a comienzos del siglo XX se produjeron dos fenómenos que demostraron el gran interés existente por informar sobre el juego del foot-ball. Por un lado, en 1902 se inició una etapa en la que varios redactores y periodistas de la época publicaron reflexiones sobre la adaptación de los términos futbolísticos (Nomdedeu 2019 en prensa). En ese mismo año, apareció en Madrid el periódico Heraldo del Sport, dedicado prevalentemente al automovilismo y al fútbol, aunque también abordó cuestiones de ciclismo, esgrima, yachting o hípica, entre otros deportes. En 1903, se fundó el periódico deportivo Gran vida (1903-1935), la Revista de Sport, el diario general $A B C$ (1903-) y se publicó el Manual de sport de Antonio Viada, que puede ser considerada la primera aportación bibliográfica completa y moderna del deporte español y la primera publicación española que trató de ilustrar y propagar el deporte a partir del modelo inglés.

Y, en tercer lugar, como han estudiado Torrebadella y Olivera (2013), la prensa deportiva en España obtuvo un impulso extraordinario en el contexto regeneracionista. Ello se demuestra por el formidable incremento del número de publicaciones en el último cuarto del siglo XIX, por la amplia propaganda del Regeneracionismo a favor de la cultura física y por los mensajes y planteamientos de este movimiento atribuidos al deporte.

Por lo tanto, el periodo objeto de atención en este estudio es un periodo de recepción del léxico futbolístico, concretamente en los textos periodísticos, en el que imperaba la novedad del nuevo juego. Ello ocasionaba la aparición de noticias asociadas a él, como la constitución de nuevos clubes o la celebración de partidos. Todavía no había surgido la preocupación por la denominación de las voces, si bien este interés estaba próximo debido, sobre todo, al caudal de anglicismos que atestaría las páginas de las publicaciones de la época desde 1902 (v. Nomdedeu 2019 en prensa).

\section{MÉTOdo De CONSTITUCióN DEL CORPUS TEXTUAL}

Para alcanzar el objetivo marcado en este estudio de presentar los textos periodísticos del periodo comprendido entre 1868 y 1899 en los que se documentan las primeras voces del fútbol, en la metodología empleada se han utilizado recursos y técnicas de análisis histórico en torno al tratamiento de las fuentes documentales originales. Para la obtención de las fuentes del periodo objeto de estudio, se ha aplicado la fundamentación heurística: por un lado, se han utilizado las aportaciones bibliográficas de Torrebadella y Olivera (2012 y 2013), Torrebadella y Nomdedeu (2014 y 2015) en torno a la educación física, el deporte y el fútbol, respectivamente, y, por otro lado, la localización de las obras en los fondos documentales, como la Biblioteca de l'Esport (Barcelona). La digitalización de los textos fundamentales de la última década del siglo XIX en 
repositorios de diferente tipo -Hemeroteca Digital de la Biblioteca Nacional de España, Biblioteca Virtual de la Prensa Histórica, Arxiu de Revistes Catalanes Antigues (ARCA) de la Biblioteca de Catalunya, Xarxa d'Arxius Comarcals, Premsa digitalitzada catalana, Hemeroteca Histórica del Ayuntamiento de Huelva o Hemeroteca digital de La Vanguardia- ha permitido el avance en las búsquedas y documentación de los términos de un modo mucho más rápido del que hubiéramos procedido al carecer de las herramientas tecnológicas actuales. Una vez documentadas las fuentes textuales, se procedió al análisis crítico de las obras y a su vaciado terminológico, con el fin de obtener las primeras documentaciones de términos del fútbol para el DHTF. También se han considerado otras fuentes secundarias historicistas para el establecimiento de una aproximación contextual necesaria para fijar el marco teórico histórico del ámbito objeto de análisis (p. ej., Bahamonde 2002 y 2011, Castro 2012, GarcíaCastell 1968, Torrebadella 2012). Estos estudios también han facilitado el análisis $\mathrm{y}$ discusión de las fuentes históricas. Todo este proceso ha permitido presentar una descripción coherente de las informaciones, redactar la interpretación de los sucesos y presentar datos léxicos novedosos.

Hay que tener en cuenta que el ámbito objeto de estudio cuenta con publicaciones - fundamentalmente manuales técnicos, reglamentos o tratados deportivos - que no se hallan en catálogos públicos. El coleccionismo existente en este sector deportivo provoca, en ocasiones, que la mejor fuente de documentación sea una biblioteca privada. A pesar de las dificultades existentes para la catalogación de los textos y la documentación de los términos, es de este modo que se puede realizar un vaciado terminológico con el objetivo de describir dicho léxico y, en último término, elaborar un diccionario histórico que recoja las primeras documentaciones textuales de las voces del fútbol y su evolución a lo largo de la historia. Por esta razón, no se descarta que vayamos descubriendo nuevas fuentes documentales a medida que vayamos avanzando en las investigaciones, motivo por el cual las aportaciones presentadas aquí no se conciben ni exponen como exhaustivas, sino como representativas y fiables.

\section{EL CORPUS TEXTUAL DEL DHTF: LOS PERIÓDICOS ENTRE 1868 Y 1899}

En este apartado, presento textos periodísticos entre 1868 y 1899, tipo de texto fundamental en el corpus textual del DHTF, cuyo establecimiento proviene de varias investigaciones encaminadas a aportar documentaciones léxicas para este diccionario. En los últimos años, se han publicado algunos estudios elaborados con el fin de recopilar fuentes bibliográficas referidas a deportes - como el de Torrebadella y Olivera (2013) - y varios estudios centrados en presentar y vaciar léxicamente las fuentes documentales de fútbol entre 1890 y 1936 - Torrebadella y Nomdedeu 2014, 2015 y 2016; Nomdedeu y Torrebadella 2016. Del total de obras documentadas en estos estudios, concretamente 85 sobre deporte y 121 sobre fútbol, hay 14 textos cuya explotación lingüística es necesaria para 
determinar el léxico del fútbol y sus características en el periodo denominado «inicios de la prensa deportiva y creación de un espacio propio» (desde la primera referencia al fútbol, 1868, hasta 1913): los textos seleccionados son 1 crónica $[\mathrm{C}], 4$ periódicos deportivos $[\mathrm{P}], 4$ reglamentos [RG], 4 tratados deportivos [TD] y 1 manual técnico [MT]:

1. 1890: Primera crónica de un partido de fútbol (Sevilla-Recreativo de Huelva). La Provincia, Huelva, 12 de marzo de 1890. [C]

2. 1897-1910: Los Deportes [P]. Es la publicación deportiva decisiva de finales del s. XIX y principios del s. XX. Actuó como plataforma de lanzamiento de diversas entidades deportivas y defendió los valores del deporte.

3. 1902. Asociación de clubs de Foot-ball de Barcelona: Reglamento de foot-ball, adoptado por la Asociación Clubs Foot-ball, s. e., Barcelona, 1902. [RG]. Primer reglamento de fútbol en español (cf. Nomdedeu 2014).

4. 1903. Asociación de clubs de Foot-ball de Barcelona: Estatutos, Reglamento. Concursos para la temporada 1903-1904, Los Deportes, Barcelona, 1903. [RG]

5. 1903. Viada, Antonio: Manual de Sport, Ed. Adrian Romo, Madrid, 1903. [TD]. Es la primera aportación bibliográfica completa y moderna del deporte español y la primera publicación española que trata de ilustrar y propagar el deporte siguiendo el modelo inglés (cf. Nomdedeu y Torrebadella 2018).

6. 1903-1935: Gran vida [P]. Una de las primeras publicaciones especializadas en deportes, pero que incluye otros asuntos de sociedad. Su subtítulo fue «revista ilustrada de sports y sociedad», al que desde 1908 se añaden los lemas «turismo, deportes, fotografía, páginas financieras».

7. 1906. Lloret, Isidro: Asociación de clubs de Foot-ball de Barcelona. Reglamento de juego, Los Deportes, Barcelona, 1906. [RG]

8. 1906-: El Mundo Deportivo [P]. Es la publicación deportiva más antigua que todavía se edita en España que se propuso realizar una amplia campaña propagandística del deporte y de la regeneración racial. Desde El Mundo Deportivo se iniciaron numerosas asociaciones deportivas, se organizaron campeonatos, se difundió el olimpismo y se plasmó toda la actualidad deportiva de la época.

9. 1910. Federación Española de Clubs de Foot-ball: Estatutos de la Federación Española de Clubs de Foot-ball: reglamento y disposiciones generales para la celebración de los partidos de foot-ball, Imp. de Layunta y Compañía, Madrid, 1910. [RG]

10. 1910. Tunmer, M. M. y Fraysse, Eugene, M. M. y Montespin, Rene barón de: Foot-ball, según los consejos de M. M. Tunmer y Fraysse, Waterpolo. JiuJitsu por el barón Rene de Montespin, Editorial Ibero-americana, Barcelona, s. a. (ca. 1910) [TD]. Esta obra ilustra una de los primeros 
intentos por incorporar las modernas prácticas físicas y deportivas que emergían en el continente europeo. ${ }^{7}$

11. 1910. Webert, Ernest: Deportes atléticos, Casa editorial Garnier Hermanos, París, s. a. (ca. 1910) [TD]. Obra perteneciente a la Biblioteca de utilidad práctica de los Manuales Garnier, es un excelente y completo manual para el entrenamiento y práctica de los deportes, cuya $1^{\underline{a}}$ edición francesa se publicó en 1905.

12. 1911-1930: Stadium [P]. Este periódico se dirigía esencialmente a la sociedad acomodada barcelonesa de las primeras décadas del siglo XX, que se incorporaba al deporte. Tenía unas secciones temáticas: «Sección doctrinal», «El apostolado del sport», «Crónica gráfica», «Nuestras Sociedades», «La moda en el sport», «De sociedad»y «Las industrias del sport». También contaba con un suplemento, con portadilla y numeración independiente, titulado «Guía del sportman».

13. 1912. Barba, Alejandro: Football, basse ball y lawn tennis. Barcelona: Ed. Sucesores de M. Soler, s. a. (ca. 1912) [TD]. Tratado básico para los inicios de la divulgación del lenguaje futbolístico en español (cf. Moreno y Nomdedeu 2019).

14. 1913. Graham, Georges: Novísimo tratado de Foot-ball. Método práctico para jugar al FOOT-BALL y apreciar la licitud y oportunidad de las jugadas. Ciencias y Letras, Barcelona, 1913. [MT]. Primera de las obras de una colección que, con el nombre «Biblioteca Deportiva», publicaba la editorial Ciencias y Letras de Barcelona. Fue la primera monografía técnica publicada en España que trataba únicamente el deporte del fútbol.

De estos 14 textos, destacan los tres periódicos deportivos barceloneses -Los Deportes (1897-1910), El Mundo Deportivo (1906) y Stadium (1911-1930) -, fundamentales en la difusión de las actividades deportivas del cambio de siglo, y el periódico madrileño Gran vida (1903-1935). Antes de llegar a 1913, el fútbol español aún se encontraba en una incipiente etapa de institucionalización y de proceso de deportivización, se mostraba como un deporte más en los primeros libros en los que aparecía - el Manual de Sport de Antonio Viada (1903); Los Sports de moda. Foot-ball, según los consejos de M. M. Tunmer y Fraysse, Waterpolo. JiuJitsu por el barón Rene de Montespin, de Tunmer y Fraysse (1910); Deportes atléticos de Ernest Weber (1910); Football, basse ball y lawn tennis de Alejando Barba (1912) - , situación que cambiaría en pocos años. Las primeras monografías técnicas de este deporte, aunque llegaron con retraso, marcaron la inflexión hacia una mejor comprensión, preparación y calidad del juego. El Novísimo tratado de

\footnotetext{
${ }^{7}$ La $1^{\mathrm{a}}$ edición francesa de esta obra corresponde a Tunmer, N. G. Et Fraysse, Eugéne: Football (Associatión), Armand Colin et Cie., París, 1897 (XV-129 p.; 17 cm.).

${ }^{8}$ V. Pujadas y Santacana (2012) para una buena descripción de Los Deportes, El Mundo Deportivo y Stadium. Para una descripción también solo de Los Deportes, v. Torrebadella y Olivera (2013).
} 
Foot-Ball. Método práctico para jugar al FOOT-BALL y apreciar la licitud y oportunidad de las jugadas de Graham (1913) fue el primer manual técnico que apareció traducido al castellano.

A estos textos, hay que incorporar la primera referencia al fútbol, publicada en El Panorama, Periódico ilustrado quincenal (Valencia) y los periódicos La Vanguardia y La Dinastía, textos que hemos ido documentando a posteriori y que, como se expone a continuación, fueron también fundamentales para la difusión del léxico del fútbol en español.

Como se observa, pues, la prensa es un tipo de documento fundamental en el corpus textual del DHTF, sobre todo porque es el medio en el que se introducen los primeros términos del fútbol y también el espacio en el que se consolidan: la primera referencia al fútbol (1868), la primera crónica de un partido (1890) y periódicos como La Vanguardia (1881-), La Dinastía (1883-1904), Los Deportes (18971910), Gran Vida (1903-1935), El Mundo Deportivo (1896-) o Stadium (1911-1930).

Las fechas que dan comienzo y cierre al periodo objeto de atención en este estudio (1868-1899) se justifican del modo siguiente. En primer lugar, el 30 de abril de 1868 se documenta la primera referencia al fútbol, un artículo titulado «El foot-ball (bola de pie) en Inglaterra» publicado en El Panorama, Periódico ilustrado quincenal (Valencia). Esta noticia aparece en un contexto en el que se disputaban partidos improvisados entre representantes de la colonia inglesa en las principales poblaciones portuarias. Frecuentemente el evento tenía como protagonista la llegada de algún buque inglés (Torrebadella, Olivera y Bou 2017: 4). En segundo lugar, en 1899 comenzó, por un lado, la transición desde un léxico del fútbol circunscrito a las noticias que iban apareciendo sobre este juego hacia otro tipo de términos mucho más descriptivos - necesarios para referirse a las acciones que se realizaban durante los partidos,$- y$, por el otro, supuso a su vez el final de una etapa caracterizada por pocos términos en inglés, antesala de otra etapa representada por la abundante presencia de anglicismos a partir de los primeros años del siglo XX (cf. Nomdedeu 2014 y 2019 en prensa). Entre ambos hitos, merece tenerse en consideración el año de 1890, fecha en la que se publicó la primera crónica de un partido de fútbol y momento a partir del cual comenzaron a aparecer, aunque tímidamente, noticias de hechos de fútbol en la prensa de información general.

La explotación lingüística de todos estos textos, que estamos llevando a cabo y de la que vamos exponiendo resultados parciales gradualmente en diversos estudios, ${ }^{9}$ es necesaria para poder ir determinando el léxico del fútbol de los orígenes y poder configurar, así, sus características en la fase en la que dicho léxico comienza a penetrar en los diferentes tipos de textos en español y se consolida de una manera definitiva. Sabemos que estos textos no son todos aquellos en los que se registran voces sobre el fútbol en el periodo analizado,

\footnotetext{
${ }^{9}$ Como en Nomdedeu (2014, 2015, 2019 en prensa), Nomdedeu y Torrebadella $(2016,2018)$ y Torrebadella y Nomdedeu $(2013,2014,2015,2016)$.
} 
puesto que vamos recopilando progresivamente notas sueltas o noticias breves que anunciaban la celebración de un partido de foot-ball en publicaciones periódicas locales, ${ }^{10}$ pero sí se trata de los periódicos fundamentales de este periodo para abordar el estudio del léxico objeto de análisis. Con todo, las recientes investigaciones evidencian que la historia del fútbol en España se halla en continua revisión y redacción. A este respecto, en la línea de las consideraciones actuales sobre la elaboración de repertorios históricos, preferimos documentar en una primera fase el léxico recogido en los textos más representativos de la historia del léxico de este juego para, en fases sucesivas, ir incorporando otras documentaciones textuales no consideradas anteriormente por no tratarse de textos fundamentales del periodo estudiado, en la línea de lo expresado por Pascual (2012: 2).

Por lo que respecta a los periódicos de información general, La Dinastía (1892) y La Vanguardia (1894), ambos de Barcelona - ciudad considerada como la principal cuna del deporte contemporáneo en España -, publicaron las primeras columnas, en donde se presentaron con cierta regularidad las primeras crónicas del fútbol español. Son dos periódicos fundamentales por lo que respecta a la difusión del léxico del fútbol en español, como se argumenta en el apartado 5 de este estudio. Tenemos constancia, no obstante, de que antes de 1890 ya se hallaban noticias sobre foot-ball en España. Saiz de Baranda (2013: 9) señala que «a mediados del siglo XIX comienzan a aparecer las primeras informaciones de carácter deportivo en la prensa española, por influencia del periodismo anglosajón y francés», pero hay que incidir en el hecho de que el fútbol no comenzó a presentarse en noticias aisladas en la prensa de distintas poblaciones españolas hasta el último tercio del siglo XIX, lejos de lo que vino a ser después el volumen de información futbolística de comienzos del XX (cf. Nomdedeu 2014 y 2019 en prensa). Esas primeras noticias del foot-ball llegaron a través de los improvisados partidos entre representantes de la colonia inglesa en las principales poblaciones portuarias. El evento solía tener como protagonista la llegada de algún buque inglés. A partir de lo que han indicado Finestres y Giménez (1999), la primera referencia al fútbol es de 1868 y fue publicada en Valencia en El Panorama, Periódico ilustrado quincenal, el 30 de abril de 1868 [1N],11 cinco años después de la creación de The Foot-ball Association en Londres (1863). La noticia, dada a conocer por Martínez (2010) y que hemos podido documentar gracias a la digitalización ofrecida por la Hemeroteca Digital de la Biblioteca Nacional de España, describía, de forma muy rudimentaria, la forma del juego,

\footnotetext{
${ }^{10}$ Hallamos informaciones de las primeras noticias y crónicas de los primeros partidos de football en las poblaciones de Jerez (El Progreso, 1870), Huelva (La Provincia, 1890), Sevilla (El Porvenir, 1890), Barcelona (La Dinastía, 1892), Tenerife (Diario de las Palmas, 1894), Bilbao (Noticiero Bilbaíno, 1894 y El Pelotari, 1894), La Coruña (Anunciador, 1894), Vigo (El Pelotari, 1895) o Madrid (La Correspondencia de España, 1898).

${ }^{11}$ Franco (2010), erróneamente, indica que es en El Progreso. Periódico político de Jerez (1 de noviembre de 1870).
} 
pero desde el punto de vista lingüístico es significativa al ya documentarse en ella las voces bola de pie, foot-ball -en los sentidos de 'balón' y 'fútbol' -, poste y percha ('larguero'). A partir de aquí, la voz foot-ball, referida al juego, se comienza a documentar en numerosos periódicos o revistas de la época como consecuencia de una simple mención de la voz al ser noticia la celebración de un acto denominado football, como, por ejemplo, en El Progreso. Periódico político de Jerez (1 de noviembre de 1870) o en el Eco Republicano de Compostela (26 de junio de 1873), momento a partir del cual fue apareciendo progresivamente en todo tipo de publicaciones periódicas, como en El Día (12/02/1883, p. 7), La Ilustración artística (14/03/1887, p. 82), La Ilustración católica (25/10/1889, n.ำ30, p. 4), Diario oficial de avisos de Madrid (28/04/1891, p. 3), El Heraldo de Madrid (3/10/1891, p. 1), Revista de España (1/1892, n.o 138, p. 199), La Época (14/7/1892, n.o 14.313, p. 3), La Iberia (22/11/1892, p. 3), La Dinastía (24/12/1892, p. 2), La Publicidad (03/03/1895, p. $3)$, etc. Y es que, como ha señalado Torrebadella (2012: 82), «en esta época el fútbol era completamente desconocido entre los españoles. Las pocas referencias que se tenían sobre este deporte llegaban a través de algunas noticias de Inglaterra, en las que habitualmente daban información de la desmedida brutalidad del juego». A este respecto, es elocuente el hecho de que la primera asociación española en practicar el fútbol, el Huelva Recreation Club, se fundara en 1889,12 21 años después de la aparición de la primera noticia sobre fútbol de que tenemos constancia. ${ }^{13}$

\section{EL PRIMER LÉXICO DEL FÚTBOL EN ESPAÑOL (1868-1899)}

Entre 1868 y 1899 se registran 55 términos del fútbol documentados por primera vez en español, todos ellos en la prensa:

${ }^{12}$ Como ha remarcado Torrebadella (2012: 82), la fecha de fundación del Huelva Recreation Club que se ha sostenido hasta hace poco tiempo (1878) no es correcta, ya que se trataba, como ha indicado Bálmont (2007), del llamado Club Inglés de Rio Tinto. Oficialmente, «el Huelva Recreation Club quedó constituido en 1889, a iniciativa de la colonia inglesa, pero todavía se trataba de una asociación recreativa, en la que se practicaban diferentes sports como pelota, cricket, lawntennis, regatas, ciclismo o foot-ball. Sin embargo, sí que puede admitirse que probablemente fuese la primera asociación española que practicó oficial y públicamente el fútbol en España» (Torrebadella, 2012: 82).

${ }^{13}$ En esta época el fútbol estaba presente en cualquier lugar en el que se encontrase una colonia inglesa con un número de jóvenes suficiente como para formar equipos y disputar partidos. La controversia de cuándo se jugó el primer partido de fútbol todavía sigue abierta. Mouriño (2003) y Domínguez (2009) se han referido a las noticias que en 1873 se imprimieron, supuestamente, en el Eco Republicano de Compostela - 26 de junio y 10 de diciembre - sobre el juego que practicaban con un balón impulsado con los pies los marineros de los barcos ingleses fondeados en el Puerto de Vilagarcía de Arousa, pero un estudio de documentación sobre la cuna del fútbol en España ha demostrado la falsedad de dicho dato (Moreno 2007). 


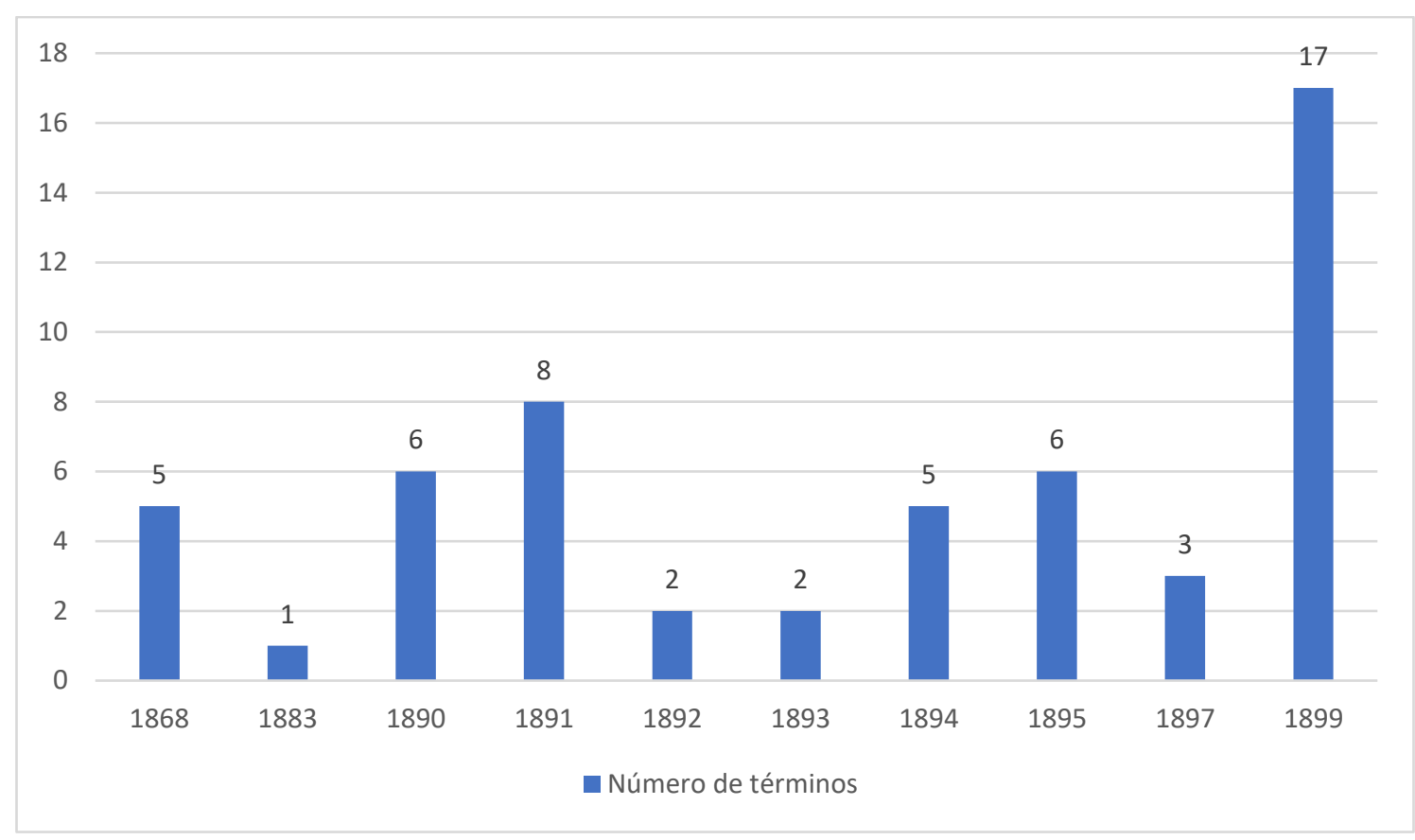

FIGURA 1: Primeras documentaciones de términos del fútbol (1868-1899)

Como se observa en la figura 1, entre 1868 y 1897 los términos del fútbol van apareciendo lentamente, algo lógico si se tiene en cuenta que en este periodo la caza y el ciclismo eran las actividades deportivas principales y el fútbol comenzaba a asomar tímidamente la cabeza. El fútbol era una actividad desconocida entre los españoles hasta esas fechas; lo que se conocía era a través de algunas noticias publicadas que llegaban de Inglaterra. A partir de 1899 el número de primeras documentaciones léxicas del fútbol aumenta notablemente (19). A este respecto, en la Tabla 1 se representan las primeras documentaciones léxicas en cada periódico:

\begin{tabular}{|c|c|c|}
\hline Año & Periódico & Términos \\
\hline 1868 & $\begin{array}{l}\text { El Panorama. Periódico Ilustrado } \\
\text { Quincenal (Valencia) }\end{array}$ & $\begin{array}{l}\text { bola de pie, foot-ball ('balón'), foot-ball ('fútbol'), } \\
\text { percha ('larguero'), poste }\end{array}$ \\
\hline 1883 & El Día (Madrid) & football \\
\hline 1890 & La Provincia (Huelva) & $\begin{array}{l}\text { botar ('sacar'), capitán, colocar ('marcar'), goal }{ }^{1} \\
\text { ('tanto'), jugador, partida }\end{array}$ \\
\hline 1891 & La Provincia (Huelva) & $\begin{array}{l}\text { arco, castillo ('portería'), juez decisor, match, } \\
\text { partido, pelotazo, pelota ('balón'), terreno }\end{array}$ \\
\hline 1892 & La Época & juego de pelota \\
\hline 1893 & $\begin{array}{l}\text { La Dinastía. Diario político, } \\
\text { literario, mercantil y de avisos }\end{array}$ & bando, campeonato \\
\hline \multirow{2}{*}{1894} & La Época & calcio \\
\hline & La Vanguardia & campo, puerta, tanto, zaguero \\
\hline \multirow[t]{2}{*}{1895} & La Vanguardia & $\begin{array}{l}\text { defensor en puerta ('portero'), delantero, intermedio, } \\
\text { medio, pelota }{ }^{2} \text { ('fútbol'), team }\end{array}$ \\
\hline & La Dinastía. Diario político, & juego de pelota a pié \\
\hline
\end{tabular}




\begin{tabular}{|c|l|l|}
\hline \multirow{2}{*}{ Año } & \multicolumn{1}{|c|}{ Periódico } & \multicolumn{1}{c|}{ Términos } \\
\hline \multirow{2}{*}{1897} & literario, mercantil y de avisos & \\
\cline { 2 - 3 } & La Ilustración artística & fuera de juego ('offside'), línea de meta \\
\hline \multirow{3}{*}{1899} & Los Deportes & football rugby \\
\cline { 2 - 3 } & La Vanguardia & $\begin{array}{l}\text { combinación, conducción, corredor ('futbolista'), } \\
\text { defensa ('la'), foot-vall, growl ('partido'), hacer goal, } \\
\text { juego ('deporte'), jugada, jugar la pelota, primer } \\
\text { espacio de tiempo }\end{array}$ \\
\cline { 2 - 3 } & $\begin{array}{l}\text { defensor, defensor de puerta ('portero'), entrada } \\
\text { ('gol'), juez de límite, linesman, segunda parte }\end{array}$ \\
\hline
\end{tabular}

TABLA 1: Periódico en los que se registran las primeras documentaciones de términos del fútbol (1868-1899)

Con anterioridad a 1890 contamos con la primera documentación de cinco términos - bola de pie, foot-ball ('fútbol' y 'balón'), percha y poste en 1868 y football en 1883. La documentación de 1868 es aislada, pues, por ahora, es la única con la que contamos hasta 1883 (El Día), en cuyo texto solo se registra una voz del fútbol: se trata de la variante gráfica football (en 1868 ya se documentó foot-ball). Por tanto, antes de 1890, la presencia de noticias de fútbol en español es casi anecdótica.

Hay que esperar a la última década del mismo siglo para hallar la siguiente referencia a este deporte, concretamente en la crónica del primer partido de football del que se tiene constancia escrita en nuestro país. ${ }^{14}$ El partido en cuestión lo disputaron el 12 de marzo de 1890 el Huelva Recreation Club contra la Colonia inglesa de Sevilla - trabajadores ingleses de la Compañía Portilla White Co - en el hipódromo Dehesa de Tablada de Sevilla (Rodríguez y Narbona 1954, Seijas 1975, Bálmont 2007, Franco 2010, Castro 2012). Esta primera crónica de un partido de fútbol de la que tenemos conocimiento, publicada el 12 de marzo de 1890 en La Provincia (Huelva) [1C], la consideramos un texto fundamental desde el punto de vista léxico, ya que fue a partir de ese momento en el que comenzaron a aparecer términos del fútbol relativos al desarrollo del juego, a las acciones, a las demarcaciones. Hasta esta fecha, las voces documentadas se referían de manera casi exclusiva a su denominación (foot-ball), pues básicamente se encontraban

${ }^{14}$ Conviene aclarar, no obstante, que es difícil saber con total certeza cuál fue el primer partido de fútbol jugado en España. Noticias recientes indican que una breve crónica (en http://olimpismo2007.blogspot.com.es/2013/02/primera-cronica-periodistica-de-un.html aparece esta referencia, aunque no hemos podido consultar directamente la noticia) de otro partido jugado en Bilbao en 1889, publicada en el diario inglés Sunderland Daily Echo and Shipping Gazette el 4 de julio de 1889, puede hacer que deba revisarse esa afirmación sobre «el primer partido de football jugado en España» referido al Sevilla-Recreativo disputado el 12 de marzo de 1890. Torrebadella, Olivera y Bou (2017) afirman que «Matters such as who brought the first football to Spain, who played the first game and where, or which was the first association to play it, whether in a casual or an organized manner, remain to be ascertained. There is probably no record of the first spontaneous game played in Spain, but the first press news can likely shed some light». Como se observa, pues, la tarea de encontrar la primera documentación textual de las voces del fútbol no es sencilla. 
referencias al juego o noticias breves que anunciaban la celebración de algún partido. En [1C] ya se registran por primera vez los seis términos siguientes: botar ('sacar'), capitán, colocar ('marcar'), goal', jugador y partida. Contamos, además, con la crónica de Salvador López Gómez publicada en La Provincia (Huelva) diez meses después, el 2 de enero de 1891 (pp. 1-2), referente al partido disputado entre el Recreativo de Huelva y el Foot-ball Club de Sevilla [2C], noticia que se publicó anteriormente en El Mercantil de Sevilla. En [2C] se informó de las medidas del terreno de juego, de la portería y de algunas acciones, y se registran por primera vez las ocho voces siguientes: arco/castillo, juez decisor, match, partido, pelota, pelotazo y terreno.

A partir de 1890, la publicación de crónicas futbolísticas, y no solo de noticias breves, conllevó que aumentara, si bien lentamente, el número de primeras documentaciones léxicas en la prensa de información general, sobre todo en La Vanguardia.

Además de las 6 primeras documentaciones de 1890 [1C] y las otras 8 de $1891[2 \mathrm{C}]$ :

- en 1892 se hallan dos primeras documentaciones, juego de pelota [La Época, en adelante LEp], pelota ('fútbol') [La Vanguardia, en adelante LVG];

- en 1893, dos términos: bando y campeonato [La Dinastía, en adelante LDi];

- en 1894, cinco términos: calcio [LEp], campo [LVG], puerta [LVG], tanto [LVG] y zaguero [LVG];

- en 1895, seis términos: defensor en puerta ('portero') [LVG], delantero [LVG], intermedio [LVG], juego de pelota a pié [LDi] medio [LVG] y team [LVG].

El artículo «La educación moderna inglesa» publicado el 18 de mayo de 1894 en la página 3 de La Vanguardia evidenció que el fútbol estaba penetrando cada vez con más fuerza en esos años incipientes, pues el columnista explicó que había visto practicar en Londres un juego denominado football muy parecido al juego del calcio florentino y proporcionó muchos detalles sobre en qué consistía y cómo se desarrollaba, lo que demuestra que en ese momento se trataba de un juego bastante desconocido en España.

Entre 1896 y 1898 únicamente se hallan tres nuevas documentaciones léxicas, ambas de 1897:

- en 1897, tres términos: football rugby [Los Deportes, en adelante LDP], fuera de juego ('offside') [Ilustración artística, en adelante IA] y línea de meta [IA].

Fue en 1899 cuando se encuentra el pico más alto de nuevos términos. Aparecieron diecisiete voces nuevas - combinación [LDP], conducción [LDP], corredor ('futbolista') [LDP], defensa (f.) [LDP], defensor [LVG], defensor de puerta ('portero') [LVG], entrada [LVG], foot-vall [LDP], growl ('partida') [LDP], hacer goal 
[LDP], juego [LDP], juez de límite [LVG], jugada [LDP], jugar la pelota [LDP], linesman [LVG], primer espacio de tiempo [LDP] y segunda parte [LVG]-, 6 de ellas registradas en el periódico La Vanguardia y 11 en Los Deportes.

De entre las 55 primeras documentaciones aportadas en este periodo, 38 se encuentran repartidas en tres periódicos: 14 en La Provincia (Huelva), 13 en Los Deportes y 11 se hallan en La Vanguardia, lo que demuestra la fuerza innovadora de las publicaciones periódicas de información general (La Provincia y La Vanguardia) y la presencia ya importante del fútbol en la prensa deportiva (Los Deportes).

La Vanguardia comenzó a ganar protagonismo como diario de referencia a partir de 1894-1895 por lo que se refiere a la transmisión de noticias futbolísticas. Fue el «periódico de empresa» que se impuso al resto, especialmente en Cataluña. Desde sus comienzos demostró interés por tratar la información deportiva: «Noticias relacionadas con los habituales deportes aristocráticos como las carreras de caballos, la caza, el tiro al pichón o los deportes náuticos, se encuentran desde los primeros números de la cabecera» (Simón Sanjurjo, 2012: 29), si bien ya se documentaron en él algunas voces del fútbol entre 1893 y 1895 : football (01 febrero 1893), match (11 marzo 1894), goal (13 diciembre 1894), campo (18 mayo 1894), bando (06 diciembre 1894), delantero (05 febrero 1895) o team (12 marzo 1895). A partir de que se comenzara a publicar la «Crónica de Sport» el 31 de octubre de 1894, aparecieron con más frecuencia noticias deportivas, firmadas al comienzo por el periodista Franco hasta 1898, año en el que la sección pasó a denominarse «Notas de Sport» (la primera es del 28 de julio de 1898), firmada por Alberto Serra. ${ }^{15}$

En la misma línea, el periódico barcelonés Los Deportes, fundado y dirigido por Narciso Masferrer, fue «la publicación periodística especializada más representativa del momento a nivel nacional» (Torrebadella y Nomdedeu 2013: 12) y «sirvió como plataforma de lanzamiento de diversas entidades deportivas y se caracterizó por el rigor de los contenidos y por la labor efectuada en defensa de los valores del deporte» (Saiz de Baranda 2013: 25). Se publicaron 520 números entre el 1 de noviembre de 1897 y el 15 de julio de $1910 .{ }^{16} \mathrm{Al}$ comienzo tuvo una periodicidad quincenal, pero se convirtió en semanal a partir del 7 mayo de 1899, justo después de la absorción en marzo del mismo año de la revista Barcelona Sport, que había sido fundada en esta ciudad en 1897 (Berasategui 2000: 158). A

${ }^{15}$ Simón Sanjurjo (2012: 30) señala 1895 como la fecha de inicio de la «Crónica de sport» y 1899 como la fecha de comienzo de «Notas de sport». Por nuestra parte, hemos documentado la primera «Crónica de sport» el 31 de octubre de 1894 y el inicio de «Notas de sport» el 28 de julio de 1898.

${ }^{16}$ Este periódico comenzó a perder importancia, sobre todo, a causa del nacimiento en 1906 de El Mundo Deportivo, periódico deportivo que vino a ocupar el espacio de comunicación que hasta entonces había ocupado Los Deportes y que se caracterizó por seguir el modelo de la prensa especializada europea, como la Gazzetta dello Sport (1897), en Italia, o l'Auto (1900), predecesora de L'Équipe (1945), en Francia, como impulsor y organizador de campañas deportivas además de información sobre los distintos deportes de la época (Berasategui, 2000: 159). 
partir de este momento, «la revista se consolidó como la cabecera deportiva más importante en Cataluña, [...] se convirtió en semanario, diversificó el contenido informativo e inició la organización de competiciones deportivas» (Pujadas y Santacana 2012: 144). Y es justamente desde el 24 de diciembre de 1899, número 43, que se halla en Los Deportes por vez primera una sección titulada «Foot-ball», momento a partir del cual el porcentaje de información futbolística aumentó notablemente. Hasta esta fecha, las noticias futbolísticas aparecieron bajo la sección «Miscelánea». Como justificación de la creación de dicha sección, en el número 44 de Los Deportes, del 31 de diciembre de 1899, A. Serra, autor del artículo publicado con el título «Foot-ball», aludía a la normalidad con la que estaba penetrando el fútbol en Barcelona:

es el sport del día que ha tomado plena carta de naturaleza en esta capital. El deporte que cautiva la atención de todos los aficionados y que practican por las tardes de los días festivos en el ex Velódromo de la Bonanova los distinguidos socios del "Foot-ball Club Barcelona", del "Foot ball Club Catalán" y los del "Team Inglés". (p. 1119)

Y justo a continuación de este artículo, escribió, en el mismo número, la crónica de los partidos entre «los teams del "Foot-ball Club Barcelona" y el "Football Club Català"» (p. 1119) y el «Match entre el team inglés y el team mixto de socios de los clubs "Català" y "Barcelona"» (p. 1120), la primera crónica en sentido estricto publicada en Los Deportes. En ella se usaron los términos match, team, foot-ball, partido, jugada, bando, combinación, conducción, jugador, juego, pelota, campo, growl ('partida'), corredor ('futbolista'), primer espacio de tiempo, defensa (f.), jugar la pelota, entrada ('goal', 'tanto'), puerta y hacer goal.

El resto de periódicos no recogieron tantas primeras documentaciones léxicas, lo cual no significa que no documenten en ellos términos del fútbol ni que no dieran espacio a los diversos fenómenos futbolísticos dignos de ser contados en ese momento. ${ }^{17}$ Por ejemplo, La Dinastía. Diario político, literario y mercantil (14/10/1883-30/06/1904), con tres primeras documentaciones léxicas (bando, campeonato y juego de pelota a pié), demostró una cierta apertura a la recepción de las noticias deportivas en general al crear, a partir del 3 de noviembre de 1892, la columna de «Sport Internacional», primera columna de deportes de la prensa de noticias española, redactada por E. Font Valencia.

Además de los periódicos señalados como textos en los que se incorporan las primeras documentaciones léxicas de una palabra del fútbol, existen numerosos periódicos durante los últimos años del siglo XIX que dan noticia de acontecimientos futbolísticos: El País, El Cardo, El Día, La Ilustración católica, el Diario oficial de avisos de Madrid, El Heraldo de Madrid, la Revista de España, La Iberia o La Publicidad. Con todo, aún nos hallamos en una fase muy inicial como para establecer diferencias entre los tipos de términos a partir de su uso, un dato que

\footnotetext{
${ }^{17}$ Con la excepción de La Provincia (Huelva), en donde documentamos las dos primeras crónicas en español, pero que en los próximos meses de este periódico no nos constan noticas referentes a este ámbito.
} 
tendremos en consideración para el vaciado terminológico realizado en los textos fundamentales de la primera década del siglo XX y con el que podremos distinguir las realizaciones léxicas puntuales de las usadas comúnmente por las plumas de las distintas épocas.

De los 55 términos del fútbol documentados por primera vez en textos en español hasta 1899, hay ocho extranjerismos (14,54\%), concretamente siete anglicismos -foot-ball/football/foot-vall, football rugby, goal', growl, linesman, match, team- y un italianismo -calcio. Como contrariamente se podría haber hipotetizado, entre los primeros términos del fútbol registrados en el siglo XIX no se encuentra un elevado porcentaje de extranjerismos. Fue a partir de 1900 cuando los anglicismos futbolísticos poblaron las páginas de los diferentes medios escritos en los que iban apareciendo, en paralelo al aumento exponencial de la terminología del fútbol en diversos tipos de textos. Por ejemplo, como se ha explicado en Nomdedeu (2015), de las 11 primeras documentaciones de 1900 con las que contamos por ahora - back [LVG], campo de juego [LDi], goal ${ }^{1}$ [LVG], goalkeeper [LVG], half-back [LVG], juez árbitro [LVG], juez de línea [LVG], marco [LVG], referee [LVG] [LDi], juego limpio [LVG] y lineman [LVG]-, 6 son anglicismos. Esta tendencia siguió en los dos años siguientes. En 1901 hallamos 3 nuevas documentaciones - forward [LVG], marcar goal [LVG] y shuot [LVG]-, de las cuales 2 son anglicismos, la última derivada del shoot, que dará lugar al chut actual. Y 9 nuevas documentaciones en 1902 - free-kick [LVG], guarda meta [LVG], medio [LVG], offside [LVG], penalty [LVG], penalty-kick [LVG], saque de castigo [LVG], saque libre [LVG] y saque de rincón [LVG]-, de las que 4 son anglicismos. Se confirma, pues, que el periódico de información general La Vanguardia fue fundamental por lo que respecta a la incorporación de términos futbolísticos en la última década del siglo XIX y los primeros años del siglo XX. Asimismo, la aparición del Reglamento de foot-ball publicado por la Asociación Clubs Foot-ball de Barcelona en 1902, primer reglamento de fútbol publicado en español, fue decisiva en cuanto a la aparición de anglicismos se refiere (Nomdedeu 2014), pues 30 de los 67 términos que aparecieron en dicho reglamento son extranjerismos (44,8\%). En este sentido, esta publicación fue tan significativa que en 1902 comenzó una discusión lingüística en textos periodísticos, iniciada por Antonio Viada (1902a-1902i) y que se prolongaría hasta Federico Caro (1919), en la que se dirimió la necesidad o no de castellanizar los anglicismos deportivos que iban llegando al español. Participaron de esta controversia «Un Delantero» (19 de enero de 1902), Antonio Viada (en una serie de artículos publicados entre febrero y diciembre de 1902: 1902a-1902i), Mariano de Cavia (1908a y 1908b), Carlos Miranda (1908), un artículo anónimo (1908), Luis Zozaya (1908), Narciso Masferrer (1911 y 1912), Francisco Bru (1918), Mofreu (1919) y Federico Caro (1919). Los textos en los que se llevó a cabo este debate fueron (cf. Nomdedeu 2014 y 2019 en prensa):

- El artículo firmado por «Un Delantero» titulado «Foot-ball. La cuestión 
del día», publicado en el número 3 de la revista Los Deportes el 19 de enero de 1902.

- Ocho artículos firmados por Antonio Viada, quien colaboró con la revista Los Deportes de 1897 a 1910, «Sobre el vocabulario deportivo» (1902a1902i) en los que abordaba la cuestión de la adaptación de los términos deportivos extranjeros firmados y en los que expuso la intención de españolizar los anglicismos del deporte.

- El artículo «Universidad Popular de Madrid. Palabras usadas en la crítica de deportes por los periodistas. El foot-ball» que Miguel Salvador publicó en 1907 en el número 8 de La Tipografía. Revista mensual ilustrada de artes gráficas.

- Los artículos publicados por Mariano de Cavia en El Imparcial titulados «Balompié», el 1 de agosto de 1908 (1908a), y «El balompié en marcha», el 5 de agosto de 1908 (1908b).

- El artículo «¿Balompié?... ¿Bolapié?... ¿Bolopié?... Para Mariano de Cavia» publicado por Carlos Miranda (1908) en El Liberal el 2 de agosto de 1908.

- El artículo titulado «No se dice foot-ball, dígase balompié» publicado por un autor anónimo en El País el 3 de agosto de 1908.

- El artículo publicado por Luis Zozaya (1908) en el Heraldo de Madrid el 3 de agosto de 1908, titulado «Balompié y bolapié».

- El artículo publicado por Francisco Bru (1918) en el número 74 de MadridSport, del 28 de febrero de 1918, titulado «El balompié y sus voces».

- El artículo publicado por Moreu (1919) en Madrid-Sport, n. ํㅜ 128, el 13 de marzo de 1919, titulado «Filología deportiva».

- El artículo publicado por Federico Caro (1919: 1) en Madrid-Sport, n. ${ }^{\circ}$ 120, el 16 de enero de 1919, titulado «Tecnología futbolística».

Observamos, por tanto, que la preocupación por la traducción de los anglicismos futbolísticos no fue una cuestión inmediata ante la aparición de los primeros términos del fútbol a finales del siglo XIX, sino que surgió con posterioridad, durante la primera década del siglo $\mathrm{XX}$, a partir de la aparición del primer reglamento de fútbol publicado en español en 1902.

\section{CONCLUSIONES}

El fútbol es uno de los campos de mayor innovación léxica desde su aparición en el último tercio del siglo XIX. Con la metodología seguida para este tipo de análisis como el presentado, se demuestra que se puede ir acotando la historia del léxico 
del fútbol español a partir de la documentación de las fuentes fundamentales por medio de la consideración de la representatividad de las obras y de los autores, gracias a la labor realizada entre historiadores del deporte, documentalistas y lingüistas.

Las 55 primeras documentaciones léxicas presentadas en este estudio entre 1868 y 1899 demuestran que el juego del fútbol comenzaba a divulgarse con cierta regularidad en este periodo y que el espacio escogido era el de la prensa general, entre 1868 y 1896, y también la deportiva, desde 1897. Con todo, la información futbolística ocupaba aún poco espacio en las columnas de los periódicos de finales del siglo XIX. Por los datos extractados, La Vanguardia y Los Deportes son periódicos fundamentales por lo que respecta a la transmisión de terminología futbolística. Entre estos términos, la mayor parte de ellos aluden a zonas del terreno de juego, a demarcaciones y a acciones, estas últimas a partir de la aparición de las primeras crónicas periodísticas. Los anglicismos están casi ausentes en estos años embrionarios en lo relativo al fútbol en España, pero poblarán las páginas de los diferentes textos durante la primera década del siglo $\mathrm{XX}$, no antes.

Con este estudio, se deja abierta una primera aproximación historiográfica del vocabulario futbolístico, centrada en las 55 primeras documentaciones léxicas en textos entre 1868 y 1899, que se podrá seguir ampliando a medida que vayan surgiendo otras fuentes y otro tipo de fuentes (como, por ejemplo, las literarias) hasta ahora desconocidas o no documentadas. En la misma línea que Torrebadella, Olivera y Bou (2017) con respecto al análisis de los orígenes del fútbol en España, las tareas de recopilar información y de validar las fuentes para construir una historiografía precisa del léxico del fútbol español desde sus orígenes hasta su consolidación son complejas y aún está por terminar.

\section{BIBLIOGRAFÍA}

Agulló AlbuiXeCH, R. (2003), Diccionario de Términos deportivos, Madrid, Espasa.

ALBA, E. (2010), «La primera referencia al foot-ball en España», Cuadernos de fútbol, Revista del Centro de Investigaciones de Historia y Estadística del Fútbol Español (CIHEFE), 6 de enero de 2010. Disponible en: <http://www.cihefe.es/ cuadernosdefutbol/2010/01/la-primera-referencia-al-football-en-espana/>.

ALBA, E. (2011), «Nuevas consideraciones sobre la primera referencia al foot-ball» (Jerez, 1870), Cuadernos de fútbol, Revista del Centro de Investigaciones de Historia y Estadística del Fútbol Español (CIHEFE), 22 de junio de 2011. Disponible en: $<$ http://www.cihefe.es/cuadernosdefutbol/2011/06/nuevas-consideraciones-sobrela-primera-referencia-al-foot-ball-en-espana-jerez-1870/>.

AleiXandre-Benavent, R., Agulló AlbuiXech, R., Agulló Calatayud, V. Y VALDERRAMA-ZURIÁN, J. C. (2007), «Terminología y lenguaje deportivo del fútbol», Cultura, Ciencia y Deporte, año 4, 6(2), 117-123.

ANÓNIMO (1908), «No se dice foot-ball, dígase balompié», El País, 3 de agosto de 1908, 1. 
AsociaCión ClUBS FOOT-BALl De BARCELONA (1902), Reglamento de foot-ball, Barcelona, 13 págs.

BAHAMONDE MAGRO, Á. (2011), «La escalada del deporte en España en los orígenes de la sociedad de masas, 1900-1936», en Atletas y ciudadanos. Historia social del deporte en España 1870-2010, X. Pujadas (ed.), Madrid, Alianza Editorial, 89-123.

BÁLMONT, A. (2007), 1884-1899: La verdad sobre el fútbol sevillano entre 1890 y 1893: Aclaraciones a los historiadores del F. C. Sevilla, Madrid, Bubok Publishing S. L.

BARBA, A. (1912), Football, basse ball y lawn tennis, Barcelona, Ed. Sucesores de M. Soler.

BERASATEGUI, M. L. (2000), «Datos para la historia de la prensa deportiva en Cataluña», Revista General de Información y Documentación 10(1), 153-169. Disponible en: $<$ http://revistas.ucm.es/index.php/RGID/article/view/RGID0000120153A>.

BRU, F. (1918), «El balompié y sus voces», Madrid-Sport, 74, 28 de febrero de 1918, 1-2.

CARO, F. (1919), «Tecnología futbolística», Madrid-Sport, 120, 16 de enero de 1919, 1.

CASTAÑÓN RODRíGUEZ, J. (1991), Léxico de fútbol en la prensa deportiva española: 1938-1988, tesis doctoral, Valladolid, Universidad de Valladolid.

CASTAÑón RODRÍGUEZ, J. (2004), Diccionario terminológico del deporte, Gijón, Ediciones Trea, S. L.

CASTAÑÓN RODRÍGUEZ, J. (2005), «Universidad, comunicación y lenguaje periodístico del fútbol en América y España», Revista Digital Universitaria, 6(6), 1-12. Disponible en: <http://www.revista.unam.mx/vol.6/num6/art53/jun_art53.pdf >.

CAstro, J. (2012), Orígenes del fútbol sevillano. La olvidada memoria británica, Madrid, Punto Rojo Libros.

CAVIA, M. de (1908a), «Balompié», El Imparcial, 1 de agosto de 1908, 1.

CAVIA, M. de (1908b), «El balompié en marcha», El Imparcial, 5 de agosto de 1908, 1.

DELANTERO, Un (1902), «Foot-ball. La cuestión del día», Los Deportes, 3, 19 de enero de 1902, 38-40.

Domínguez AlmansA, A. (2009), Historia social do deporte en Galicia, 1850-1920, Vigo, Editorial Galaxia.

FINESTRES, J. Y GIMÉNEZ, S. (1999), Història dels clubs de fútbol. 1 pròlegs. Orígens del fútbol als Països Catalans, Barcelona, Edicions del País Valencià, S. A.

FRANCO SÁNCHEZ, J. L. (2010), "La partida de "football" (la primera que se juega en España)», Cuadernos de fútbol, Revista del Centro de Investigaciones de Historia y Estadística del Fútbol Español (CIHEFE), 6, 1 de enero de 2010. Disponible en: $<$ http://www.cihefe.es/cuadernosdefutbol/2010/01/lapartidade-\%E2\%80\%9Cfootb all\%E2\%80\%9D-la-primera-que-se-juega-enespana/>.

GARCÍA-CASTELL, J. (1968), Historia del futbol català, Barcelona, Aymà.

GÓMEZ TORREGO, L. (2003), "Aspectos gramaticales del lenguaje del fútbol en España», en Estudios ofrecidos al profesor José Jesús de Bustos Tovar, Girón Alconchel, J. L., Iglesias Recuero, S., Herrero Ruiz de Loizaga, F. J. y Narbona, A. (coords.), vol. 2, Madrid, Ed. Complutense, 969-991.

GómEZ TORREGO, L. (2010a), «Aspectos gramaticales del lenguaje del fútbol», marcoELE, $11,132-149$.

GÓMEZ TORREGO, L. (2010b), «Aspectos semánticos del lenguaje del fútbol en España», marcoELE, 11, 150-158.

GÓMEZ TORREGO, L. y MAPELLI, G. (2010), «Bibliografía sobre el lenguaje del fútbol», marcoELE, 11, 173-175. 
GRAHAM, G. (1913), Novísimo tratado de Foot-ball. Método práctico para jugar y apreciar la licitud y oportunidad de las jugadas, Barcelona, Ilustrado con numerosos grabados, Ciencias y Letras.

GUTIÉRREZ GUTIÉRREZ, D. (1991), Estructura y lenguaje de la crónica de fútbol, tesis doctoral, Madrid, Universidad Complutense de Madrid.

KARAG, A. (1958), Diccionario de los deportes, Barcelona, Dalmau y Jover.

KOCH, W. (1998), Diccionario de fútbol, Barcelona, Ed. Paidotribo (trad. de Simon, W., Fussball Von A-Z, Begriffe, Fakten, Berlin, Sportverlag, 1991).

LAGARDERA OTERO, F. (1996), «Notas para una historia social del deporte en España», Historia de la Educación, 14-15, 151-172.

LOUREDA LAMAS, Ó. (1997), «Hacia la caracterización de la función de la metáfora en el lenguaje del fútbol», Lenguaje y textos, 10, 185-212.

LOZA Olave, E. Y CASTAÑón RODRÍGUEZ, J. (2010), Términos deportivos de origen extranjero, Logroño, Servicio de Publicaciones de la Universidad de la Rioja.

MARTínEZ PATÓN, V. (2010), «1868: La primera noticia sobre "foot-ball” en España», Cuadernos de fútbol, Revista del Centro de Investigaciones de Historia y Estadística del Fútbol Español (CIHEFE), 12, julio de 2010. Disponible en: $<$ http://www.cihefe.es/cuadernosdefutbol/2010/07/1868-la-primera-noticia-sobrefoot-ball-en-espana/>.

MASFERRER, N. (1911), «Periodistas deportivos I. Antonio Viada», Mundo Deportivo, 305, 23 de noviembre, $1-2$.

MASFERRER, N. (1912), «Periodistas deportivos III. José Elías y Juncosa», Mundo Deportivo, 316, 8 de febrero, 1.

MiRANDA, C. (1908), «¿Balompié?... ¿Bolapié?... ¿Bolopié?... Para Mariano de Cavia», El Liberal, 2 de agosto, 2.

Moreno Bolaños, A. (2007), Análisis de una cita periodística que cuestiona la Cuna del Fútbol en España, Minas de Riotinto, edición del autor. Disponible en: $<$ https://es.scribd.com/doc/9007128/VILAGARCIA-DE-AROUSA-Y-SU-ONTAJEDEL-FOOTBALL-EN-1873>.

Moreno Villanueva, J. A. Y NOMDEDEu Rull, A. (2019), «Los inicios de la divulgación del lenguaje futbolístico: Football, base ball y lawn tennis de Alejandro Barba (1912)», en Lengua de la ciencia y Lenguajes de especialidad, Garriga, C., Pascual, M. L. y Pedraza, M. B. (eds.), en Anexos de Revista de Lexicografía, 42, A Coruña, Universidade da Coruña, 135-150.

MoreU, A. S. (1919), «Filología deportiva», Madrid-Sport, 128, 13 de marzo, 1-2.

MOURIÑo RAÑo, P. (2003), Arosa S. C. Iniciación al fútbol en España, Vilagarcía, Ediciones Lea.

NOMDEDEU RULL, ANTONI (2001), «Marcas temáticas: hacia una sistematización de las marcas de deporte y de fútbol en los diccionarios generales de español» [CD-ROM], en Perspectivas recientes sobre el Discurso, Moreno, A. I. y Colwell, V. (eds.), León, AESLA-Universidad de León, s. p.

NOMDEDEU RULL, ANTONI (2003a), «La terminología deportiva de la prensa escrita en los diccionarios generales de español: análisis y propuesta lexicográfica», en $I$ Jornada Internacional sobre la Investigación en Terminología y Conocimiento Especializado, Bach, C. y Martí, J., Barcelona, Instituto Universitario de Lingüística Aplicada-Universidad Pompeu Fabra, 56-64. 
NOMDEDEU RulL, A. (2003b), «La terminología del deporte en los diccionarios generales del español», Revista de lexicografía, 9, A Coruña, Universidade da Coruña, Ed. Toxosoutos, S. L., 57-95.

NOMDEDEU RULL, A. (2004a), «El léxico del fútbol en la lexicografía general monolingüe del español» en De Lexicografia: actes del I Symposium Internacional de Lexicografia (Barcelona, 16-18 de maig de 2002), Battaner, P. y DeCesaris, J. (eds.), Barcelona, Instituto Universitario de Lingüística Aplicada-Universidad Pompeu Fabra, 619640.

NOMDEDeU RulL, A. (2004b), Terminología del fútbol y diccionarios: elaboración de un diccionario de especialidad para el gran público, tesis doctoral, Barcelona, Universitat Autònoma de Barcelona. Disponible en: <http://www.tdx.cat/handle/10803/4872>.

NOMDEDEU RULL, A. (2008a), «Variation dénominative et conséquences conceptuelles», en Le vocabulaire scientifiche dans les langues africaines. Pour une approche culturelle de la terminologie, Diki-Kidiri, M. (dir.), Paris, Éditions KARTHALA, 181-200.

NOMDEDEU RULL, A. (2008b), «Hacia una reestructuración de la marca de deportes en Lexicografía», en Actas del II Congreso Internacional de Lexicografía Hispánica. El diccionario como puente entre las lenguas y culturas del mundo (Alicante, 19-22 de septiembre de 2006), 764-770, Alicante, Biblioteca Virtual Miguel de Cervantes. Disponible en: <http://www.cervantesvirtual.com/obra/hacia-una-eestructuracinde-la-marca-de-deportes-en-lexicografa-0/>.

Nomdedeu Rull, A. (2009a), Diccionario de fútbol, en Anexos de Revista de Lexicografía, 11, A Coruña, Servizo de Publicacións-Universidade da Coruña.

NOMDEDEU RULL, A. (2009b), «Evolución del DRAE en la representación del léxico de especialidad», Revista Española de Lingüística, 39(1), 141-166. Disponible en: $<$ http://sel.edu.es/rsel/index.php/revista/article/view/57>.

NOMdeDeu RulL, A. (2014), «Diccionario Histórico de Términos del Fútbol (DHTF): el léxico en el primer reglamento de fútbol (1902) publicado en español», Cuadernos del Instituto Historia de la Lengua, año VII, 9, 185-205.

Nomdedeu Rull, A. (2015), «Primeras documentaciones del Diccionario Histórico de Términos del Fútbol: contexto, textos fundamentales y términos (1890-1899)», Estudios de Lexicografía, revista bimensual del grupo Las dos vidas de las palabras, 1, 60-73, febrero 2015. Disponible en: <http://issuu.com/ldvp/docs/elex_febrero _de_2015?e=15360805/11251537>.

NomDedeu RulL, A. (2019, en prensa), «Las aportaciones de Antonio Viada (1902) a la estrategia españolizadora del lenguaje deportivo anglosajón. Estudio a propósito del Diccionario Histórico de Términos del Fútbol», Boletín de la Real Academia Española, cuaderno 320 (julio-diciembre).

NOMDEDEU RUlL, A. Y MÁRQUEZ RojAS, M. J. (2001), «Los anglicismos en la terminología del fútbol: motivaciones y consecuencias lingüísticas» [CD-ROM], en Perspectivas recientes sobre el Discurso, Moreno, A. I. y Colwell, V. (eds.), León, AESLAUniversidad de León, s. p.

Nomdedeu Rull, A. Y TORREBADELla I FliX, X. (2016), «Diccionario Histórico de Términos del Fútbol (DHTF): textos fundamentales del período inicial (1890-1913)» en Lengua de la ciencia e historiografía, en Anejos de Revista de Lexicografía, Pérez Pascual, J. I. y Garriga Escribano, C. (coords.), A Coruña, Universidade da Coruña, 207-229.

Nomdedeu Rull, A. Y TORREbadella I FliX, X. (2018), «Antonio Viada: regeneracionismo, deporte y lengua española. La institucionalización de las 
primeras voces del fútbol en España en el Manual del Sport (1903)», Arbor. Ciencia, Pensamiento y Cultura, 194-789, julio-septiembre, a470. Disponible en: $<$ http://arbor.revistas.csic.es/index.php/arbor/article/view/2283/3250>.

OTERO CARVAJAL, L. E. (2003), «Ocio y deporte en el nacimiento de la sociedad de masas. La socialización del deporte como práctica y espectáculo en la España del primer tercio del siglo XX», Cuadernos de Historia Contemporánea, 25, 169-198. Disponible en: <http://revistas.ucm.es/index.php/CHCO/article/view/CHCO0303120169A >.

PAlACiOS AlCAINE, A. (1999), «Aspectos lingüísticos de la prensa deportiva: la crónica futbolística», en La lengua y los medios de comunicación, Garrido Medina, J. (ed.), Madrid, Universidad Complutense de Madrid, 3350-3361.

PASCUAL, J. A. (2012), «Sobre el léxico deportivo. A propósito de un corpus modular para el NDHE», en II Congreso de la Cátedra Luis Michelena, Lakarra, J. A., Gorrochategui, J. y Urgell, B. (coords.), Bilbao, Servicio Editorial de la Universidad del País Vasco, $1-22$.

PeltZer, F. (2007), Léxico del fútbol, Buenos Aires, Academia Argentina de Letras.

PÉREZ SÁNCHEZ, A. P. (2013), El género de la retransmisión deportiva radiofónica: condicionantes y pautas para la idoneidad de la retransmisión futbolística en la era digital, tesis doctoral, Salamanca, Universidad Pontificia de Salamanca.

POLO, A. (1996), El diccionario de fútbol, Madrid, Ediciones Altea, S. A.

PUJADAS, X. Y SANTACANA, C. (2003), «El club deportivo como marco de sociabilidad en España. Una visión histórica (1850-1975)», Hispania. Revista Española de Historia, 214, 505-522. Disponible en: <https://www.researchgate.net/publication/ 307741726_El_club_deportivo_como_marco_de_sociabilidad_en_Espana_Una_vi sion_historica_1830-1975>.

PUjADAS, X. Y SANTACANA, C. (2012), «Prensa, deporte y cultura de masas. El papel del periodismo especializado en la expansión social del deporte en Cataluña hasta la guerra civil (1890-1936)», Historia y Comunicación Social, 17, 139-155. Disponible en: $<$ http://revistas.ucm.es/index.php/HICS/article/view/40603>.

PuyAl i ORTigA, J. Ma (1972), Aportación al estudio de las lenguas especiales: Terminología futbolística, tesis de licenciatura, Barcelona, Universidad de Barcelona.

Real Ramos, E. (2003), Diccionario Espasa de términos deportivos, Madrid, Espasa.

Ricco, A. y NOMDEDEU Rull, A. (2012), «El léxico del fútbol en la poesía: Alberti, Hernández, Benedetti», Didáctica. Lengua y Literatura, 24, 295-314. Disponible en: $<$ http://revistas.ucm.es/index.php/DIDA/article/view/39929>.

RIVERO HerRAIZ, A. (2005), Deporte y modernización. La actividad física como elemento de transformación social y cultural en España, 1910-1936, Sevilla, Wanceulen Editorial Deportiva, S. L.

RODRÍGUEZ FERNÁNDEZ, Á. Y NARBONA, F. (1954), Enciclopedia general de los deportes, Madrid, Delegación Nacional de Deportes.

SAIZ NoEDA, B. (2010), «Notas sobre la retórica del lenguaje futbolístico», marcoELE, 11, 196-227. Disponible en: <http://marcoele.com/retorica-del-lenguaje-futbolistico/>.

SAIZ DE BARANDA ANDÚJAR, C. (2013), Mujeres y deporte en los medios de comunicación. Estudio de la prensa deportiva española (1979-2010), tesis doctoral, Getafe, Universidad Carlos III. Disponible en: <http://earchivo.uc3m.es/handle/ 10016/16505>. 
SALVADOR, M. (1907), «Universidad Popular de Madrid. Palabras usadas en la crítica de deportes por los periodistas. El foot-bal», La Tipografía. Revista mensual ilustrada de artes gráficas, 8, 75-76.

SEIJAS, E. (1975), «Ingleses y mineros introducen el fútbol en España», Historia y Vida, 83, 93-97.

SILVEIRA, D. (1996), «Diccionario de términos futboleros», en Pelé estuvo aquí, Pereira, J. M., Barcelona, Montesinos, 133-182.

SIMÓN SANJURJO, J. A. (2012), «Conquistando a las masas: el impacto del deporte en la prensa española, 1900-1936», Recorde: Revista de História do Esporte, 5(1), julio, 1-40. Disponible en: <http://www.sport.ifcs.ufrj.br/recorde/pdf/recordeV5N1_2012 _17.pdf $>$.

TERUEl SÁEZ, A. (2007), Vocabulario de fútbol, Gijón, Trea.

Tolares Caballero, G. (2009), El lenguaje del futbol. Prontuario de términos y frases características en México, México, Editorial Trillas.

TORREBADELla FliX, X. (2011), Repertorio bibliográfico inédito de la educación física y el deporte en España (1800-1939), Madrid, Fundación Universitaria Española.

TORREBADELLA FLIX, X. (2012), «Orígenes del fútbol en Barcelona (1892-1903)», RICYDE, Revista Internacional de Ciencias del Deporte, 27, 80-102. Disponible en: $<$ http://www.redalyc.org/articulo.oa?id=71024521007>.

TORREBADELLA I FLIX, X. Y OLIVERA BETRÁN, J. (2012), «Las cien obras clave del repertorio bibliográfico español de la educación física y el deporte en su proceso de legitimación e institucionalización (1807-1938)», Revista General de Información y Documentación, 22, 119-168. Disponible en: <http://revistas.ucm.es/index.php /RGID/article/view/39669>.

TORREBAdella FliX, X. y Olivera Betrán, J. (2013), «The Birth of the Sports Press in Spain Within the Regenerationist Context of the Late Nineteenth Century», The International Journal of the History of Sport, 30(18), 2164-2196. Disponible en: $<$ http://www.tandfonline.com/doi/abs/10.1080/09523367.2013.854775>.

TORREBADELla FliX, X., OliVERA BETRÁN, J. y BOU, M. M. (2017), «The Origins of Football in Spain: From the First Press Appearance to the Constitution of the First Clubs (1868-1903)», The International Journal of the History of Sport, 34(7-8), 471-497. Disponible en: <https://doi.org/10.1080/09523367.2017.1365707>.

TORREBADELLA FliX, X. Y NOMDEDEU RULL, A. (2013), «Foot-ball, futbol, balompié... Los inicios de la adaptación del vocabulario deportivo de origen anglosajón», RICYDE, Revista Internacional de Ciencias del Deporte, 31, 5-22. Disponible en: $<$ http://www.cafyd.com/REVISTA/ojs/index.php/ricyde/article/view/531>.

TORREBADELlA FliX, X. Y NOMDEDEU RULL, A. (2014), «Bibliographic repertoire of Football in Spain (1900-1936). 121 works to interpret the social impact of football in contemporary history», Apunts, Educación Física y Deportes, 115, 1r trimestre (gener-març), 7-32. Disponible en: <http://www.revista-apunts.com/ hemeroteca? article $=1621>$.

TORREBAdELla Flix, X. Y NOMdedeu RULL, A. (2015), «Los primeros libros del fútbol publicados en España (1900-1919)», Revista General de Información y Documentación, 25(1), 113-139. Disponible en: <http://revistas.ucm.es/index.php/RGID/ article/view/48985>.

TORREBAdella Flix, X. y NOMdedeu Rull, A. (2016), «La popularización del fútbol en España. Análisis del fenómeno a través de la literatura especializada del fútbol 
(1920-1936)», Revista General de Información y Documentación, 26(1), 119-146. Disponible en: <http://revistas.ucm.es/index.php/RGID/article/view/53040>.

TUNMER, M. M., FrAYSSE, W. y MONTESPIN, R. barón de (1910), Foot-ball, según los consejos de M. M. Tunmer y Fraysse, Waterpolo. Jiu-Jitsu, Barcelona, Editorial Iberoamericana.

VIADA, A. (1902a), «¿En qué quedamos? A Narciso Masferrer», Los Deportes, 7, 16 de febrero, 100-102.

VIADA, A. (1902b), «Sobre el vocabulario deportivo. A Narciso Masferrer», Los Deportes, 10, 16 de marzo, 147-149.

VIADA, A. (1902c), «Sobre el vocabulario deportivo II», Los Deportes, 12, 30 de marzo, 179180.

VIADA, A. (1902d), «Sobre el vocabulario deportivo III», Los Deportes, 16, 27 de abril, 243245.

VIADA, A. (1902e), «Sobre el vocabulario deportivo IV», Los Deportes, 21, 1 de junio, 323325.

VIADA, A. (1902f), «Sobre el vocabulario deportivo V», Los Deportes, 24, 22 de junio, 371372.

VIADA, A. (1902g), «Sobre el vocabulario deportivo VI», Los Deportes, 33, 24 de agosto, 507-508.

VIADA, A. (1902h), «Sobre el vocabulario deportivo VII», Los Deportes, 35, 7 de septiembre, $539-540$.

VIADA, A. (1902i), «Sobre el vocabulario deportivo VIII», Los Deportes, 51, 28 de diciembre, 787-788.

VIADA, A. (1903), Manual del sport, Madrid, Librería Internacional de Romo.

Vivas Holgado, J. (1998), El fútbol. Léxico, Deporte y Periodismo, Cáceres, Universidad de Extremadura.

Weber, E. (1910), Deportes atléticos, París, Casa editorial Garnier Hermanos.

ZOZAYA, L. (1908), «Balompié y bolapié», Heraldo de Madrid, 3 de agosto, 3. 